\title{
Correlation of prognostic factors and outcome of Microsurgical Tubal Recanalisation
}

\author{
Shilpa.MN ${ }^{1}$, B Shilpa Shivanna ${ }^{2}$, Gopal $\mathrm{N}^{3}$ \\ ${ }^{1}$ Assistant Professor , ${ }^{2}$ Associate Professor, ${ }^{3}$ Professor, Department of OBG Adichunchangiri Institute of \\ Medical Sciences
}

\begin{abstract}
:
Objective:1)To study the outcome of microsurgical tubal recanalisation.

2) To analyse the various factors affecting the pregnancy rate following microsurgical tubal recanalisation.

Method: It is a retrospective clinical study conducted on 45 women who underwent microsurgical tubal recanalisation at Adichunchangiri institute of medical sciences from January 2006 to June 2013.

Results: The overall pregnancy rate after microsurgical tubal anastomosis was $55.5 \%$ with $72 \%$ of live birth rate. Loss of only child was the main reason for requesting sterilisation reversal. Pregnancy rate was noted to be significantly more statistically in women aged $<30$ years, interval between sterilisation and reversal of $<2$ years, when post reversal tubal length $>5 \mathrm{~cm}$ and isthmo-isthmic type of anastomosis. Though the pregnancy rate was more $62.9 \%$ in women who underwent reversal after laparoscopic sterilisation when compared to Pomeroy's method $44.4 \%$ there was no stastistical significance.

Conclusion: Microsurgical reversal of tubal sterilisation is a good option for patients who want a child for various reasons after tubal sterilization and cannot afford IVF. Those with least amount of tubal destruction had better chances of pregnancy. Laparoscopic sterilisation should be preferred during sterilisation procedure, ligation should be done at isthmus and good length of tube preserved .
\end{abstract}

Key words: Tubal recanalisation,reversal,pregnancy rate

\section{Introduction}

Tubal sterilisation is the most prevalant family planning method practised in our country .In 2009, $48.3 \%$ of married women were estimated to use a contraceptive method and about three-fourths of them were using female sterilization ${ }^{1}$.More than $45.5 \%$ women undergoing sterilisation belong to young reproductive age group of 20 to 25 years.Approximately $1 \%$ of these women subsequently seek reversal of procedure due to unforeseen circumstances ${ }^{2}$

The gold standard for recanalisation has been microsurgical tubal recanalisation through laparotomy. Laparoscopy can be used as an alternative route but requires high expertise ${ }^{3}$. Though an option of in-vitro fertilisation is widely available but due to economic constraints people go for microsurgical tubal recanalisation as a first option.

\section{Objectives}

1)To study the outcome of microsurgical tubal recanalisation.

2)To analyse the various factors affecting the pregnancy rate following microsurgical tubal recanalisation.

\section{Materials and Methods}

It is a retrospective clinical study conducted on 45 women who underwent microsurgical tubal recanalisation in OBG department at Adichunchangiri institute of Medical Sciences from January 2006 to June 2013.

A detail history taking and examination was carried out before the operation.Apart from routine investigations required for a major surgery, baseline evaluation to rule out other contributing factors for infertility including husband's semen analysis was done.

Tubal anastomosis was performed bilaterally in all cases under magnification with microsurgical instruments. The occluded ends of tube was identified and resected till there was complete excision of pathological tissue. A two-layer closure using 6 ' 0 ' vicryl was performed. First bite was taken at 6 o'clock position, i.e., mesentric border and later at 3, 9, and 120'clock positions. Serosa was approximated similarly.Tissue handling was atraumatic and tissues were kept moist at all times by heparinised normal saline irrigation. Unipolar electrocoagulation was used for hemostasis. Patency checked after anastomosis by methylene blue test. 


\section{Results}

45 women undergoing sterilisation reversal by microsurgical technique were included in our study. At the time of surgery the mean age of women was 27.5 years. The youngest patient was 23 year old and the oldest was of 39 years of age. The main reason for seeking reversal was death of the only child in $66 \%$ cases followed by death of male child in $22 \% .25$ out of $45(55.5 \%)$ women who underwent reversal conceived out of which $72 \%$ had live birth and $12 \%$ had ectopic pregnancy .

Table1: Patient's profile and pregnancy rate

\begin{tabular}{|c|c|c|c|c|}
\hline Profile & No of patients $(n=45)$ & Pregnancy $(n=25)$ & Percentage & Statistical analysis \\
\hline \multicolumn{5}{|c|}{ Age (years) } \\
\hline$<25$ & 6 & 4 & 66.6 & \multirow{3}{*}{$\mathrm{p}$ value $=0.078$} \\
\hline $26-30$ & 20 & 15 & 75 & \\
\hline$>36$ & 5 & 1 & 20 & \\
\hline \multicolumn{5}{|c|}{ Interval between sterilisation and reversal(years) } \\
\hline$<2$ yrs & 12 & 9 & $75 \%$ & \multirow{3}{*}{$\mathrm{p}$ value $=0.078$} \\
\hline $6-9$ yrs & 6 & 2 & $33.3 \%$ & \\
\hline$>10 \mathrm{yrs}$ & 6 & 1 & $16.6 \%$ & \\
\hline
\end{tabular}

Table 2: Operative factors affecting pregnancy rate

\begin{tabular}{|c|c|c|c|c|}
\hline Operative factors & No. of cases $(n=45)$ & $\begin{array}{l}\text { Pregnancy } \\
(n=25)\end{array}$ & Percentage & Statistical analysis \\
\hline \multicolumn{5}{|c|}{ Tubal length after recanalisation } \\
\hline$<5 \mathrm{~cm}$ & 8 & 1 & $12.5 \%$ & \multirow[t]{3}{*}{$\mathrm{p}$ value $=0.008$} \\
\hline $6-8 \mathrm{~cm}$ & 25 & 14 & $56 \%$ & \\
\hline$>9 \mathrm{~cm}$ & 12 & 10 & $83.3 \%$ & \\
\hline \multicolumn{5}{|l|}{ Site of anastomosis } \\
\hline Isthmo-isthmic & 22 & 17 & $77.2 \%$ & \multirow[b]{4}{*}{$\mathrm{p}$ value $=0.028$} \\
\hline Isthmo-ampullary & 18 & 7 & $38.8 \%$ & \\
\hline Ampullo-ampullary & 4 & 1 & $25 \%$ & \\
\hline Cornu-isthmal & 1 & 0 & & \\
\hline \multicolumn{5}{|c|}{ Sterilisation technique } \\
\hline Falope ring & 27 & 17 & $62.9 \%$ & \multirow{2}{*}{$\mathrm{p}$ value $=0.824$} \\
\hline Pomeroy's method & 12 & 8 & $44.4 \%$ & \\
\hline
\end{tabular}

Pregnancy rate was $83.3 \%$ when final tubal length was $>8 \mathrm{~cm}$ and only $12.5 \%$ when the tubal length was $<5 \mathrm{~cm}$ which was statistically stignificant. The patients who underwent isthmo-isthmic type of anastomosis had higher chances of pregnancy $(77.2 \%)$ which was statistically significant when compared to other types of anastomosis. Pregnancy rate was $75 \%$ when the mean duration between sterilisation and microscopical reversal of tubal recanalisation was $<2$ years which was statistically significant. Though the pregnancy rate was higher $(62.9 \%)$ in women who underwent reversal after laparoscopic sterilisation when compared to Pomeroy's method (44.4\%) there was no stastistical significance.

\section{Discussion}

The factors that dictate success or failure of tubal recanalisation are multiple in number. In our study the overall conception rate was $55.5 \%$ ( 25 out of 45 cases) of which 18 had live births( $72 \%), 4$ had abortion and 3 cases were ectopic pregnancies. This is comparable to study by Kim et al where overall pregnancy rate was $54.8 \%$ with a delivery rate of $72.5 \% \%^{4}$. In study done by Jayakrishnan et al overall pregnancy rate was $58.8 \%{ }^{5}$. In a similar study done by Jain et al overall $60 \%$ pregnancy rate was achieved ${ }^{6}$.

Majority of women seeking tubal recanalisation were in the age group of 25 to 30 years (44.4\%) which is similar to study done by Biswas and Mondal $50.8 \%{ }^{7}$. A higher conception rate of $73.5 \%$ was seen in women under 30 years which is comparable to study done by Brar et al where fertility rate was $68 \%$. A higher conception rate in younger women may be attributed to their greater fertility potential ${ }^{8}$.

Death of only child or all children was the commonest reason for reversal of sterilisation(66\%) which coincides with the study by Jain et al where $70 \%$ of womensought reversal for death of all children ${ }^{6}$.

The pregnancy rate was $75 \%$ when reversal was done within 2 years. Kalaichelvi et al found that $87 \%$ of women conceived when recanalisation was done within a year of sterilisation and the success dropped to $16.6 \%$ when the interval was more than 10 years ${ }^{9}$. 
In our study the commonest site of anastomosis was isthmo-isthmic $48 \%$ followed by isthmoampullary $40 \%$ which coincides with the studies by Brar et al and Biswas et al where the commonest type of anastomosis was isthmo-isthmic in $48 \%$ and $49 \%$ respectively ${ }^{7,8}$.

Pregnancy rate was $77 \%$ in isthmoisthmic anastomosis and $38 \%$ following isthmoampullary anastomosis. 2 cases of ectopic pregnancy was seen in isthmoampullary and 1 case in isthmo-isthmic anastomosis. $72 \%$ intrauterine pregnancies were seen in women who underwent isthmo isthmic anastomosis which is similar to study by Kalaichelvi et al where $76.2 \%$ intrauterine pregnancies were seen in women with isthmo isthmic anastomosis 9 .

In our study about $82.2 \%$ women had final tubal length of $>6 \mathrm{~cm}$. The pregnancy rate was $83.3 \%$ when tubal length was $>8 \mathrm{~cm}$ and only $12.5 \%$ when it was $<5 \mathrm{~cm}$.Jain et al confirmed the importance of reconstructed tubal length where $83.3 \%$ pregnancy rate was noted when tubal length was $>8 \mathrm{~cm}^{6}$

\section{Conclusion}

The factors of successful tubal recanalisation were age $<30$ years, the interval between sterilisation and reversal $<2$ years, site of anastomosis being isthmo-isthmic and length of tube $>5 \mathrm{~cm}$.

With the shift away from microsurgical training, the treatment trend appears to be increasingly towards IVF; however, surgery is still the preferred choice of treatment for selected cases and in those who cannot afford IVF.

Since any women undergoing sterilisation can become a candidate for reversal, laparoscopic sterilisation should be preferred, ligation should be done at isthmus and good length of tubes preserved .

\section{References}

[1]. India and Family planning-An overview Department of Family and Community Health, World Health Organization, 2009-11-25

[2]. Michael J. Slowey, Charles C. Coddington. Microsurgical tubal anastomoses performed as an outpatient procedure. Fertility and sterility 1998;69:492-5

[3]. Novy MJ. Tubal Surgery or IVF-making the best choice in the 1990s. Int J Fertility 1995; 40:291-302

[4]. Kim S H, Shin C J, Kim J G et al.Microsurgical reversal of tubal sterilization.Fertility sterility 1997 Nov;68:865-70

[5]. Jayakrishnan K and Baheti .Laparoscopic Tubal sterilization reversal and fertility outcome. J of Human Reproductive sciences SepDec 2012; 4(3):125-29

[6]. Jain M, Jain P, Garg R et al. Microsurgical tubal recanalization: a hope for hopeless. Indian J Plast Surg. 2003;36:66-70.

[7]. Biswas and Mondal.Evaluation of women undergoing sterilisation reversal and subsequent pregnancy outcome. J Ind Med Assoc 2006;104:182-85

[8]. Brar MK, Kaur JS. A study of microsurgical renastomosis of thefallopian tubes for reversal of sterilization. J Obst Gyn India 2000;6:75-77

[9]. Kalaichelvi A, Swarnalatha R,Premalatha R.Is reversal of sterilisation feasible? J obst Gyn India 2001;51:120-22 